\title{
Evaluation of Public Health Policies Addressing Childhood Obesity in The EU 28
}

\author{
*Marta Trenor Lacour and Carlos Martin Saborido \\ Health Technology Assessment Unit, Universidad Francisco de Vitoria, Spain
}

Submission: April 19, 2017; Published: April 21, 2017

*Corresponding author: Marta Trenor Lacour, Health Technology Assessment Unit, Unidad de Tecnologias Sanitarias, Universidad Francisco de Vitoria, Carretera Pozuelo-Majadahonda Km 1.80028223 Pozuelo de Alarcon, Madrid, Spain, Tel: (+34) 91.351.03.03; Fax: (+34) 91.351.17.16; Email: marta.trenor@ufv.es

\begin{abstract}
Obesity has become a very serious problem to population and Institutions since it's demonstrated to be a critical risk factor for noncommunicable diseases and it's included in the WHO International Classification of Diseases as a disease. That is the reason why tackling childhood obesity has become a top priority for EU member states. But there is a lack of knowledge about the effects of interventions and actions carried out in the EU member states have had. The objective of this study is to describe the scientific evidence on interventions and actions to address childhood obesity in EU member states and synthesize the results. This paper aims to raise the importance and awareness of healthcare managers and policy-makers about implementing actions to prevent childhood obesity.
\end{abstract}

Keywords: Obesity; Public Health; Systematic review

Abbreviations: EU: European Union; ECOG: European Childhood Obesity Group; JRC: Joint Research Center

\section{Introduction}

One of the greatest problems that is concerning the EU member states is the increasing in prevalence of overweight and childhood obesity at psychological level (low academic performance, Social exclusion, low self-esteem as well as because its association with risk factors such as hypertension, diabetes, cardiovascular diseases, etc [1]. resulting in the development of associated secondary diseases and high levels of premature mortality and also described as a disease by itself [2]. Childhood obesity is an important predictor of obesity in adults $[3,4]$. In fact, about $60 \%$ of children who are overweight before puberty will also be obese adults [5]. It can be argued that obesity is reaching epidemic proportions, and is increasingly recognized as a major public health problem [6]. This fact makes highlights the need to take measures to tackle obesity, especially in children. Institutions and governments have been sensitized in this regard and have designed and implemented some actions and policies to stop this epidemic disease. In almost all European countries, specific commissions and groups have been set up to study, prevent and treat obesity, such as the European Childhood Obesity Group (ECOG) in Belgium, the European Association for the Study of Obesity (EASO), in Europe, etc.

Interesting initiatives and programs have been developed and the focus has been on promoting physical activity with many initiatives, especially in schools, where children spend most of their time, and also focus on healthy diets, consumption of fruits and vegetables, the development of physical exercise programs and the ongoing training of parents and teachers, or interventions such as: prohibiting vending machines for sugary drinks and snacks or prohibiting the sale of these products in schools that have a cafeteria [7]. All expert groups and programs that have been created with this aim, agree on the need to act and implement public health interventions from institutions, schools and family environment, they also coincide in the difficulty of installing and implementing these policies and the need to evaluate them in terms of efficiency, effectiveness, and so on.

Following the implementation of the different policies carried out in the EU member states we found a great variability in the endpoints, both qualitative and quantitative (decreased BMI, improvement in nutritional knowledge etc. That variability makes it very difficult to reach a single conclusion applicable to all cases. The study design variability includes the heterogeneity of the group to which these interventions are applied, the countries in which the policies have been generated or the duration of the policies among others. The objective of this study was to describe the scientific evidence regarding the effectiveness of health interventions to address childhood obesity in EU member states and to synthesize the results. 


\section{Juniper Online Journal of Public Health}

\section{Discussion}

After the search strategy in the electronic database, Medline, we got 363 potentially relevant studies. Just 4 of them met the inclusion criteria, which were: Studies published from January 2000 until September 2016 with an intervention carried out in any of the EU member states in 0-18 year's old children. The study design and the quality of evidence differed from one study to another. One of the included studies is a pilot clusterrandomized controlled trial [8]. Two of them were clusterrandomized controlled studies $[9,10]$ and one was a quasiexperimental study [11].

Different interventions have also been applied in the 4 studies. While in two of them. We found an intervention in which parents were involved by attending training workshops about healthy habits, physical activity and nutrition knowledge $[10,11]$. In other study the intervention was directly applied to the children [9] assessing the student's knowledge and the improvement in healthy habits, through questionnaires, after attending special lessons; and in Verbestel et al. [8] a family-based intervention aiming at increasing healthy food consumption was carried out on the whole family and measured in children.

About study duration, heterogeneity is shown among the four selected studies. Intervention in Kocken et al. [9] lasted 18 weeks and the follow up was 6 months. In both McGowan et al. [10] and Willis et al. [11] the intervention was applied during 8 weeks but the follow up was 12 months in the first one [10] and just 8 weeks in the second [11]. Finally, in Verbestel et al. [8] both intervention and follow up lasted 12 months. Those findings make unclear how long it should take a tackling-obesity program to be successful.

Effectiveness of studies has been analyzed based on anthropometric outcomes, changes in habits and nutritional knowledge; A relative BMI decrease $(\mathrm{P}<0.05)$ was observed in children who attended the healthy life style intervention in Verbestel et al. [8]. In Kocken et al. [9] the experimental group knew significantly more about healthy food than the control group $(\mathrm{P}<0.01)$, but there was no significant effect on attitude, behavioral control and intention regarding the consumption of low-calorie extra products.

It is also observed an improvement in nutritional habits in McGowan et al. [10] study with a significant effect on parental feeding behavior and children's intake of vegetables $(\mathrm{P}=0.003)$ and healthy snacks $(\mathrm{P}=0.009)$. And finally, in Willis et al. [11] study, parents reported increased self-efficacy and ability to encourage good behavior $(\mathrm{P}<0.001)$. Both parents and children increased consumption of healthy food $(\mathrm{P}<0.01)$. It is shown that, when parents are involved and participate in the intervention the results is better $[8,10]$. Our search findings draw attention on the few studies found in EU28 and showed heterogeneity in terms of population, type of intervention, intervention design and endpoints.

\section{Conclusion}

Although childhood obesity has become a serious problem, there is a lack of studies describing public health policies or interventions that address obesity in children and a great variety in the design, the duration, and the implementation of them. That heterogeneity makes it difficult to reach a consensus for policy makers in terms of designing or applying public health policies. Specially, the short follow-up in the studies prevent us to know the time to the effect extinction and therefore to decide what is the most long-lasting intervention. On the other hand, it's shown that good results could be obtained if the intervention involves parents too. This suggests that interventions to address obesity in the future should include the whole child environment, including parents and teachers. As found in this review, health intervention addressing obesity in children could be effective, but there is still room for improvement in future studies. More needs to be done to plan and execute successful health interventions.

\section{References}

1. Dietz WH (1998) Health consequences of obesity in youth: childhood predictors of adult disease. Pediatrics 101(3 Pt 2): 518-525.

2. WHO (2017) International Classification of Diseases. WHO, Geneva, Switzerland.

3. Serdula MK, Ivery D, Coates RJ, Freedman DS, Williamson DF, (1993) Do obese children become obese adults? A review of the literature. Prev Med 22(2): 167-177.

4. Lobstein T, Frelut ML (2003) Prevalence of overweight among children in Europe. Obes Rev 4(4): 195-200.

5. Deshmukh Taskar P, Nicklas TA, Morales M, Yang SJ, Zakeri I, et al. (2006) Tracking of overweight status from childhood to young adulthood: the Bogalusa Heart Study. Eur J Clin Nutr 60(1): 48-57.

6. Swinburn B, Gill T, Kumanyika S (2005) Obesity prevention: a proposed framework for translating evidence into action. Obes Rev 6(1): 23-33.

7. Hannan P, French SA, Story M, Fulkerson JA (2002) A pricing strategy to promote sales of lower fat foods in high school cafeterias: acceptability and sensitivity analysis. Am J Health Promot 17(1): 1-6.

8. Verbestel V, De Coen V, Van Winckel M, Huybrechts I, Maes L, et al. (2014) Prevention of overweight in children younger than 2 years old: a pilot cluster-randomized controlled trial. Public Health Nutr 17(6): 1384-1392.

9. Kocken PL, van Kesteren NM, Buijs G, Snel J, Dusseldorp E (2015) Students beliefs and behaviour regarding low-calorie beverages, sweets or snacks: are they affected by lessons on healthy food and by changes to school vending machines? Public Health Nutr 18(9): 15451553.

10. McGowan L, Cooke LJ, Gardner B, Beeken RJ, Croker H, et al. (2013) Healthy feeding habits: efficacy results from a cluster-randomized, controlled exploratory trial of a novel, habit-based intervention with parents. Am J Clin Nutr 98(3): 769-777.

11. Willis TA, George J, Hunt C, Roberts KP, Evans CE, et al. (2014) Combating child obesity: impact of HENRY on parenting and family lifestyle. Pediatr Obes 9(5): 339-350. 
This work is licensed under Creative Commons Attribution 4.0 Licens DOI: 10.19080/JOJPH.2017.01.555567

\section{Your next submission with Juniper Publishers will reach you the below assets}

- Quality Editorial service

- Swift Peer Review

- Reprints availability

- E-prints Service

- Manuscript Podcast for convenient understanding

- Global attainment for your research

- Manuscript accessibility in different formats

( Pdf, E-pub, Full Text, Audio)

- Unceasing customer service

Track the below URL for one-step submission https://juniperpublishers.com/online-submission.php 